\title{
HIV-Associated Neurocognitive Disorders: The Relationship of HIV Infection with Physical and Social Comorbidities
}

\author{
Ellen M. Tedaldi, ${ }^{1}$ Nancy L. Minniti, ${ }^{2}$ and Tracy Fischer ${ }^{3}$ \\ ${ }^{1}$ Department of Medicine, Temple University School of Medicine, Philadelphia, PA 19140, USA \\ ${ }^{2}$ Department of Physical Medicine and Rehabilitation, Temple University Hospital, Philadelphia, PA 19140, USA \\ ${ }^{3}$ Department of Neuroscience, Temple University School of Medicine, Philadelphia, PA 19140, USA
}

Correspondence should be addressed to Ellen M. Tedaldi; etedaldi@temple.edu

Received 23 August 2014; Accepted 29 January 2015

Academic Editor: Viroj Wiwanitkit

Copyright (C) 2015 Ellen M. Tedaldi et al. This is an open access article distributed under the Creative Commons Attribution License, which permits unrestricted use, distribution, and reproduction in any medium, provided the original work is properly cited.

\begin{abstract}
The prevalence of HIV (human immunodeficiency virus) associated neurocognitive disorders (HAND) will undoubtedly increase with the improved longevity of HIV-infected persons. HIV infection, itself, as well as multiple physiologic and psychosocial factors can contribute to cognitive impairment and neurologic complications. These comorbidities confound the diagnosis, assessment, and interventions for neurocognitive disorders. In this review, we discuss the role of several key comorbid factors that may contribute significantly to the development and progression of HIV-related neurocognitive impairment, as well as the current status of diagnostic strategies aimed at identifying HIV-infected individuals with impaired cognition and future research priorities and challenges.
\end{abstract}

\section{Introduction}

HIV-1 infection often results in varying degrees of neurocognitive dysfunction, ranging from mild impairment to frank dementia, collectively termed HIV-associated neurocognitive disorders (HAND) [1]. In its latest revision, the Diagnostic and Statistical Manual- (DSM-) 5 categorizes mild and major neurocognitive disorders on the basis of presumed etiology, association with behavioral disturbances, and degree of severity [2]. Although infection with the virus itself is included in the list of possible explanations for cognitive dysfunction among HIV-infected individuals, in clinical practice there remains the ongoing challenge of establishing the impact of the virus as the source of impairment, in relation to a variety of numerous clinical, social, and psychological factors that may contribute to HAND [3-14]. For example, neurocognitive impairment is often seen in cardiovascular disease and sleep disorders, in both HIV negative and positive persons [15-22]. With the addition of successful combination antiretroviral therapy (cART) and patients living longer with
HIV, these comorbidities are highly prevalent in the aging HIV population [23-28]. There are diagnostic issues related to the sensitivity to detect degrees of impairment especially in the ethnically and educationally diverse HIV populations of the current US epidemic where normative data may be lacking [10,29-38]. HAND may be the diagnosis of exclusion as there are no definitive biomarkers or "gold standard" assays to confirm this diagnosis [39].

The spectrum of neurocognitive disorders has evolved in the contemporary treatment era [11, 40-45]. The Frascati criteria, based on a consensus panel convened by the National Institute of Mental Health (NIMH) and National Institute of Neurological Diseases and Stroke (NINDS) in 2007, are the basis for distinguishing the categories of HAND: asymptomatic neurocognitive impairment (ANI), minor neurocognitive disorder (MND), and HIV-associated dementia (HIVD) [1]. As widely reported elsewhere, there has been a significant decline in HIV-D but a higher persistence of the minor categories, with frequently cited percentages of $20 \%$ for HIV$\mathrm{D}$ and as much as $50 \%$ for minor cognitive disorders $[11,46]$. 


\section{Neuropsychological Assessment}

Tools for assessing neurocognitive disorders include a variety of established, as well as emerging, technologies that include neurocognitive testing batteries, neuroimaging, and biomarkers $[29,36,45,47-56]$. This review will highlight some of the challenges and controversies that make assessment and diagnosis of neurocognitive disorders in HIVinfected persons a complex process that will necessitate revised strategies.

It has been established that HIV infection impairs cognition through a variety of mechanisms including CNS entry of the HIV-1 infected monocyte derived macrophages that cross the blood-brain barrier to result in a cascade of events including release of cytokines and viral products that can disrupt endothelial barriers and affect neuronal pathways [5759]. Chronic inflammation and ongoing HIV replication that persists despite peripheral HIV suppression from antiretroviral therapy may compartmentalize in various areas of the CNS leading to dysregulation of neuronal pathways [60-63].

The neurocognitive profile of HAND has included deficits in psychomotor slowing, impaired episodic memory, prospective memory, attention and working memory, and verbal fluency $[11,42,45,64]$. In addition to the immunologic and virologic status of infected persons, coexisting conditions that contribute to cognitive status include medical conditions and/or psychiatric disorders, substance abuse, and education/literacy (Figure 1) [12, 15, 33, 65-73]. The dilemma for clinicians and scientists is to delineate the role of the virus from other influences on neurocognition. The standard neuropsychological test battery can be labor intensive and requires trained personnel to administer and evaluate it. While several rapid screening instruments have been developed that can detect cognitive decline in HIV-infected persons, there is a paucity of comparative normative data in matched non-HIV populations [33, 47, 51, 53, 55, 56, 74-83]. Demographically adjusted normative data (i.e., adjustments to scores based on the subject's age, education, and/or race) are essential for accurately assessing HAND. In many cases, however, these data are lacking when comparison groups are needed for individuals of low socioeconomic status (SES) or of a racial or ethnic minority. Most neuropsychological tests are developed and normed on members of the majority culture, offering little to no information regarding test performance of members of racial/ethnic minorities, those with limited or no formal education and poor literacy, or those who grew up in very different circumstances (e.g., rural environments). Clinicians are often left with poorly matched normative groups and subsequent limitations in interpreting scores. This lack of appropriate normative information can falsely classify members of a minority culture as having cognitive decline or dementia. Inappropriate diagnosis of HAND can have profound negative implications, leading to inappropriate medical intervention, reduced self-esteem, negative financial repercussions, reduced functional independence, and misdirection of future planning. Functional capacity assessment also has limitations in the neurocognitive evaluation toolbox. These are often self-reported data, which have inherent variability issues, and some instruments are not culturally or educationally suited to administer in diverse population [49, 84-87].

\section{Social Comorbidities Effecting Cognition}

3.1. Education. The influence of demographic variables such as age, education, ethnicity, and sex on neuropsychological test results has been widely observed and their influence is significantly related to most cognitive domains in varying degrees [88]. Despite this awareness, many neuropsychological tests do not stratify their data based on these variables and, as such, the effects of demographic characteristics on particular tests are unknown. Even when tests are stratified by age or education, little information is available on how those from disadvantaged backgrounds or individuals with low literacy may perform, and recent investigations suggest that these variables are critical to understanding neurocognitive test performance. For example, it has been observed that African Americans often obtain lower scores on a broad range of cognitive tasks in comparison to their non-Hispanic white counterparts, although the reasons for these discrepancies are not entirely clear [89-91]. Educational attainment has been used as a means for controlling these differences as there are often variations in years of education between African-Americans and Caucasians. Investigators will use covariance or matching procedures as a means of equating racial groups on years of education before comparing test performance. One hypothesis put forth to account for these differences is disparities in educational quality that exist across racial and ethnic groups [92-94]. Numerous studies have indicated that reading ability is a better predictor of cognitive performance than years of education in African Americans and individuals of disadvantaged socioeconomic backgrounds $[30,93,95]$. In a study of $\mathrm{HIV}$-infected participants, racial and ethnic minorities had lower levels of literacy than nonminority subjects. Those with the highest discrepancy between reading ability and educational attainment had worse neuropsychological performance, while minority status was not associated with test performance, while minority status was not associated with test performance [96]. This demonstrates that, for some cohorts of HIV+ subjects, literacy is a better marker of educational experience and may account for observed differences in racial groups [97]. Therefore, individuals with low levels of literacy require special consideration when interpreting test results, and particular care should be taken to avoid overpathologizing patients with HIV. It should be noted that low levels of literacy and/or limited educational opportunity are also associated with more rapid age-related cognitive and functional decline and higher rates of dementia in general and should be considered as a possible contributory or confounding factor in the diagnosis of HAND [93]. These findings underscore the need for appropriate normative groups in the assessment of HAND, as HIV disproportionately affects ethnic minorities and those from disadvantaged educational backgrounds.

3.2. Poverty and Excessive Exposure to Trauma. In addition to education, other "social comorbidities" that may impact cognition among HIV-infected individuals include poverty and chronic exposure to trauma [98-100], which may adversely 


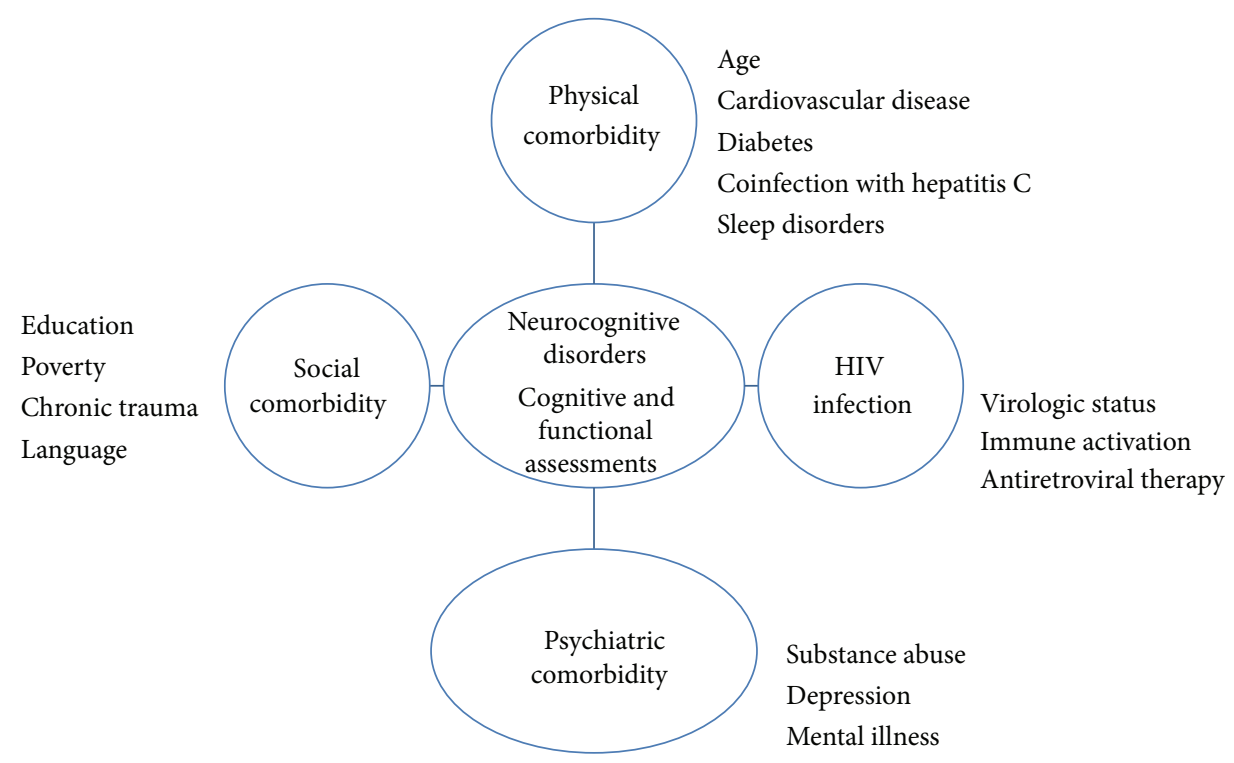

FIGURE 1: Neurocognitive disorders: role of HIV infection, comorbidities, and assessments.

affect the "cognitive reserve" of individuals subject to these conditions prior to contracting HIV. Cognitive reserve refers to the development of extensive neuronal connections that can protect neurons when they are subjected to injury through oxidative stress or inflammation [101]. The amount of reserve can be influenced by positive (education, new task) or negative neuroplasticity (poverty, isolation) [81, 100-104]. For HIV-infected populations, which are overrepresented in impoverished communities, chronic exposure to limited resources, violence, or trauma can erode neurocognitive reserves with resultant impairment that may be additive with that resulting from HIV and/or other conditions $[49,85,86$, 100, 105-107].

\section{Physical Comorbidities Effecting Cognition}

4.1. Aging. A multitude of physical comorbidities have been shown to effect cognition in general populations: age, cardiovascular/metabolic disease, sleep disorders, and coinfections, such as hepatitis C virus (HCV) [17, 19, 20, 67, 108-114]. Age is a major risk factor for dementia, with $0.8 \%$ of persons being 60-65 years old in the US reported to have dementia from any etiology [115]. The US HIV population is poised, therefore, to see more cases of dementia; $19 \%$ of the current HIV population and $5 \%$ of new HIV diagnoses are people over 55 years of age $[25,116]$. The HIV associated nonAIDS medical conditions. the HIV associated Non-AIDS conditions (HANA) and the aging of the HIV population will contribute to the expansion of the cognitively impaired population of older individuals.

Two long-standing cohorts of HIV positive and HIV negative men and women, the Multicenter AIDS Cohort (MACS) and the Women's HIV Interagency Study (WIHS), respectively, provide unique longitudinal data that can elucidate the relative contribution of HIV infection to mortality. In early initiators of HIV therapy and the HIV negative cohorts, the risk for non-AIDS related mortality was comparable [117]. As longevity with HIV infection improves with earlier treatment, the neurocognitive disorder burden will not only increase but may also evolve differently with longer durations of immune activation [40, 118-121]. The pathophysiology of age-related neurocognitive disorders may be similar to and synergistic with those in HIV, including chronic inflammation, oxidative stress, and immune senescence. It has been noted that the clinical presentation of HIV-D, traditionally a subcortical phenomenon, is now similar to the cortical dementias, such as Alzheimer's disease [45].

4.2. Cardiovascular Disease. Cardiovascular disease (CVD) is a major contributor to neurocognitive disorders in the general population $[22,122,123]$. The development of vascular cognitive impairment involves interplay of traditional cardiovascular factors, such as hypertension, diabetes and hyperlipidemia, and behavioral ones, such as obesity and sedentary life style $[3,110,124]$. Mechanistically, they cause inflammation and oxidative stress to blood vessels and may cause cerebral hypoxia-ischemia and small vessel endothelium dysfunction. HIV infection, itself, can share these common pathways and is associated with increased vascular morbidity through elevated levels of inflammatory and procoagulant factors, atherogenesis, and endothelial alterations $[6,125-127]$.

In addition, the role of antiretroviral therapy, especially protease inhibitors, has been implicated in the development of metabolic syndrome with insulin resistance, dyslipidemia, and hypertension [26, 28, 128-131]. If obesity and cigarette smoking are included in the risk profiling for vascular disease, HIV populations are population-matched in obesity rates and exceed peer groups in smoking frequency [20,38, 132].

Reports from cohort studies and clinical trials indicate that neurocognitive performance of HIV patients with CVD risk factors is impaired [3, 10, 103, 131, 133-135]. HIV is 
disproportionately represented among African Americans and Latinos, who also bear a greater burden of CVD, as compared to other ethnic groups [136-138]. Compounded with the unfortunate realities of later presentation for care and lower rates of virologic control, the risk for vascularassociated neurocognitive disorders in these populations is greater [139-141]. The compelling clinical issue is whether CVD risk modification with optimal virologic control and metabolically favorable antiretroviral therapy will be sufficient when some of the pathogenetic mechanisms such as immune activation persist.

4.3. Sleep Disorders. Sleep disorders, especially obstructive sleep apnea, are implicated in neurocognitive dysfunction in adults $[17,18,111,112]$. The prevalence of sleep-related disorders is common in the US and there are several reports on the prevalence in HIV populations [24, 142-146]. The deleterious effects of sleep deregulation on neurocognitive performance can result from obstructive sleep apnea, medication, or coexisting depression [15]. The literature on sleep and HIV and neurocognition had focused on the CNS effects of efavirenz but this effect on sleep and neurocognition can be variable in duration [147]. Sleep disorders are also associated with other medical conditions including metabolic syndrome and cardiovascular disease [148-152]. The synergistic effect of sleep disorders and cardiovascular and metabolic complications on neurocognition in HIV patients has not been reported extensively. Our group is currently surveying a diverse group of English and Spanish speaking patients to determine the prevalence of sleep disorders and relationship to a variety of immunologic, virologic, and clinical outcomes. Whether the correction or improvement in the underlying sleep dysfunction will improve neurocognitive and functional outcomes is an area of ongoing investigation.

4.4. HCV Coinfection. Depending on the HIV population, coinfection with HCV can be found in $25 \%$ of HIV populations overall and upwards of 75-85\% in high-risk groups, such as intravenous drug users [153-155]. Cognitive impairment has been noted in HCV in higher proportions than HIV infection alone, although not consistently [7, 67, 70, 156159]. HCV shares similar pathways of immune activation and inflammation that can affect neurocognitive function [60]. $\mathrm{HCV} / \mathrm{HIV}$ coinfection is often present in individuals with other confounders of cognitive impairment such as psychiatric disorders and substance abuse [65]. With the advent of more effective therapeutic options for HCV, successful eradication of HCV may have a major salutary effect on neurocognition [160]. Improvement, however, will depend on successful control of other comorbidities, including cessation of drug use and engagement in medical care.

4.5. Illicit Drug Use. The prevalence of mental illness and substance abuse among HIV-infected patients is greater than the general population and is a significant risk factors for HIV acquisition [12, 161-165]. This population often has neurocognitive sequelae from a variety of illicit drugs, including cocaine, opiates, methamphetamine, and marijuana. The effect of illicit drugs on neurocognitive impairment has been well documented [163, 166-170] and negatively impacts the treatment of these individuals. The pathogenetic mechanisms of HAND are believed to involve increased oxidative stress and permeability of the blood-brain barrier (BBB) to neurotoxic factors, including HIV viral proteins, tat, and gp120. Given the risk for nonadherence to antiretroviral therapy among drug users, the consistency of viral suppression may be less, leading to frequent episodes of viremia and uncontrolled virus replication $[60,171-173]$.

4.6. Depression and Mental Illness. Depression is common in persons living with chronic disease including HIV and is associated with several adverse outcomes including medication nonadherence, impaired functional status, neurocognitive impairment, and mortality [33, 174-180]. Clinicians do have well established brief screening instruments for depression available to them that can be utilized repeatedly for assessment [181-183]. Neurocognitive assessment generally includes an evaluation for depression since cognitive impairment is common with this disorder and may be improved with therapeutic interventions including treatment with antiretroviral therapy [177].

Other psychiatric disorders such as schizophrenia or bipolar disease are often seen in a subset of HIV-infected persons who have substance abuse and tenuous social and economic support. They are at extremely high risk for medication nonadherence and may have the "perfect storm" of cofactors that result in neurocognitive impairment $[61,66]$.

4.7. Chronic Systemic Inflammation in HAND Pathogenesis. It remains unclear why some individuals develop a pathological correlate of the most severe form of HAND, HIV-D, and HIV encephalitis (HIVE), while the majority of infected persons do not. Yet, understanding the pathogenesis of HIVE may provide key insights into the milder forms. In HIVE, activated infected and noninfected macrophages (MФs) and microglia play a prominent role in the development and progression of disease through the secretion of chemokines, cytokines, and other inflammatory mediators that are directly or indirectly neurotoxic. Additionally, infected MФs and microglia may spread virus to noninfected cells and release viral proteins that contribute to prolonged brain inflammation and neurotoxicity (for review, please see $[59,184,185]$ ). Together, this suggests an important role of both the virus and inflammation in HIVE pathogenesis. A recent immunohistological study of brain tissue from $\mathrm{HIV}$-infected persons without encephalitis but with varying degrees of neurocognitive impairment shows phenotypical and morphological evidence of inflammation, in the absence of virus production, which is similar to, but less severe than, that seen in HIVE [63]. These findings support the notion that HAND is a continuum of the same disease process and demonstrate that inflammation, rather than virus production in the brain, bridges the milder and severe forms. These studies also reveal perivascular astrocyte activation in cortical grey matter of brain from HIVinfected persons without encephalitis that does not extend into the brain parenchyma, suggesting events at the BBB 
precede parenchymal involvement [63]. Interestingly, while CART appears to have significantly reduced the incidence of HIV-D, milder forms of HAND have become an increasing issue [41]. This is likely due to the ability of cART to slow the disease process, while the underlying mechanism driving the development and progression of HAND (i.e., chronic immune activation) continue.

Although the brain is often referred to as an "immune privileged" site, there is increasing awareness of the significant communication between the brain and peripheral immune system. Systemic administration of lipopolysaccharide (LPS) in rat and mouse models promotes neuroinflammation and neuronal loss $[62,186]$ and has been shown to exacerbate neuronal loss in animal models of neurodegenerative disease [187]. In the setting of chronic inflammatory conditions, such as HIV infection, amplified and/or prolonged immune signals from the periphery to the brain may have profound consequences on the diseased or healthy brain. This is evidenced by relapses in multiple sclerosis (MS) symptoms following systemic infection $[188,189]$ and diminished cognitive capacity seen in individuals with rheumatoid arthritis (RA) or systemic lupus erythematosus $[190,191]$, as well as other conditions associated with impaired immunity, such as ageing.

Communication pathways from the periphery to the brain are well reviewed [192-194] and involve cytokines commonly seen in systemic infections and inflammatory conditions, including interleukin- (IL-) $1 \beta$, IL-6, and tumor necrosis alpha (TNF $\alpha)$, which are also elevated in HIV infection. As put forth by Perry and colleagues in (nonHIV) diseased and aged brain [193], microglia in brain of HIV-infected persons may be "primed" to quickly switch to an activated phenotype in response to inflammatory stimuli from the periphery. This may occur during the acute phase of infection, which is associated with significant immune activation and cytokine production [195]. It is during this stage of infection that virus first appears in the brain; however, it remains unclear whether HIV infection is established in the brain at this time [196]. Once primed, microglia may launch a sustained and/or exaggerated immune response to inflammatory mediators from the periphery that impairs the function of neurons and other glia, resulting in cognitive dysfunction.

4.8. Microbial Translocation as a Source of Chronic Inflammation in HIV Infection. Microbial translocation, which refers to the passage of live bacteria and/or bacterial products (e.g., LPS) across an anatomically intact intestinal barrier, has been suggested to be a major factor in HIV-related chronic immune activation and may contribute to HAND pathogenesis. Also referred to as "leaky gut," microbial translocation can result from reduced host immunity and/or increased permeability of the intestinal lining and has been shown in a number of infectious and noninfectious chronic inflammatory diseases, including celiac disease, inflammatory bowel disease, and hepatitis B and hepatitis C [197-199]. Evidence of microbial translocation, including elevated plasma LPS, LPS-binding protein (LBP), soluble CD14 (sCD14), and bacterial $16 \mathrm{~S}$ ribosomal DNA (rDNA), has been reported by a number of groups in HIV-infected human subjects and SIV infected rhesus macaques [200-205]. While the pathogenic mechanisms involved in the loss in integrity of the mucosal barrier in HIV remain unclear, early mucosal CD4 T cell depletion and HIV-related enteropathy are believed to play a prominent role [206-209]. Seminal work by Brenchley et al. suggested that microbial translocation directly contributes to systemic innate and adaptive immune activation during chronic HIV infection and may affect the progression rate of AIDS [208]. Indeed, increased plasma 16S rDNA has been associated with greater $\mathrm{T}$ cell activation in HIV-infected subjects and reduced $\mathrm{CD}^{+}{ }^{+} \mathrm{T}$ cell restoration with cART [201]. In addition, plasma LPS and soluble CD14 (sCD14) levels, a marker associated with monocyte stimulation by LPS, are reported to be elevated in patients with HIV-D, as compared to those with normal cognition [203]. In this same study, the percent of frequency $\mathrm{CD}^{+} 6^{+}$monocytes and plasma LPS was shown to decrease in patients taking cART for at least 8 weeks [203].

4.9. CD16 ${ }^{+}$Monocytes as a Potential Biomarker for Neurocognitive Dysfunction. There is intense interest in determining the role and specificity of biomarkers that may correlate with HAND or other neurocognitive disorders. Although these assays are not currently used in routine clinical practice, they may function as a component of a diagnostic algorithm to diagnose or predict cognitive impairment [48, 210-212]. Previously, the $\mathrm{CD}^{+} 6^{+}$monocyte subset has been shown by a number of groups to be elevated in HIV infection [213-216], with an even greater frequency seen in patients with HIV-D [217]. A more profound relationship with HIV disease progression is suggested; however, when the $\mathrm{CD}_{16}{ }^{+}$monocyte subset is further subfractionated by CD163 expression, where a positive correlation with $\mathrm{CD}_{16}{ }^{+} / \mathrm{CD}_{16}{ }^{+}$ monocyte frequency and viral load, as well as $\mathrm{CD}^{+} \mathrm{T}$ cell loss in individuals with 450 cells $/ \mu \mathrm{L}$ or less, has been observed [216]. Interestingly, these cells are phenotypically similar to MФs that accumulate in HIVE brain, comprise perivascular cuffs and nodular lesions, and serve as the principal reservoir of productive virus in brain [218, 219]. Further, this increase in total brain MФs in HIVE appears to be due to trafficking of monocytes/MФs from the periphery, rather than microglial proliferation [220]. Additional studies are needed to determine whether the frequency of these monocyte subsets correlates with cognitive performance and whether $\mathrm{CD}_{16}{ }^{+}$or $\mathrm{CD} 16^{+} / \mathrm{CD}_{163}{ }^{+}$monocyte frequency can serve as a viable biomarker for HIV disease progression and neurocognitive impairment.

\section{Conclusions}

Neurocognitive disorders are evolving in the HIV population with ageing and a variety of comorbid physical, social, and psychological factors, creating a complex interplay in pathogenesis, clinical presentation, and outcomes. Important areas for research include developing validated rapid screening instruments with population-specific normative data for identifying cognitive impairment in clinical practice, advancing our current understanding of HAND pathogenesis, which will allow for the identification of potential biomarkers 
and/or targets for therapeutic intervention, and identifying and or developing behavioral interventions to prevent or treat neurocognitive disorders.

In screening for HAND, Kamminga et al. recommended several criteria for optimal screening procedures that include targeting outcome measures that are more predominant in the cART era, which are compared to the comprehensive neuropsychiatric battery in non-HIV populations, as well as instruments that have normative data in diverse populations among other criteria [34]. One important criterion is that these screens can be used in the clinical setting where resources limit more time intensive approaches. In the context of multimorbidity and HAND, the assessment and treatment challenges of an HIV-infected patient are several:

(1) the diagnosis and treatment of cofactors for HAND, such as hypertension, diabetes, obesity, and coinfection: each entity has its own particular and shared clinical and lifestyle approaches, and control and management of these significant correlates of cognition in the context of polypharmacy and drugdrug interactions with antiretroviral therapy are a challenge for adherence;

(2) behavioral and mental health interventions to address concurrent drug use and psychiatric disease that can be integrated into the clinical settings;

(3) functional assessments for frailty and cognitive impairment that will identify earlier stages for intervention;

(4) earlier detection of HIV and engagement in care: the chronic neurocognitive sequelae of HIV disease and the other comorbidities will be minimized with successful long-term adherence to therapy and to a comprehensive treatment approach.

The social comorbidities that affect HAND and other neurocognitive disorders will continue to be a particularly difficult factor to modify as HIV infection predominates in under resourced and economically marginalized communities. Translational research approaches for neurocognitive disorders will need to focus on these intersections of multiple physical and social comorbidities in a global assessment schema. The models for chronic disease management will be useful for those living with HIV/AIDS.

\section{Conflict of Interests}

The authors declare that there is no conflict of interests regarding the publication of this paper.

\section{Acknowledgment}

This work is supported by a grant from the NIMH (P30NH092177).

\section{References}

[1] A. Antinori, G. Arendt, J. T. Becker et al., "Updated research nosology for HIV-associated neurocognitive disorders," Neurology, vol. 69, no. 18, pp. 1789-1799, 2007.
[2] A. P. Association, Diagnostic and Statistical Manual of Mental Disorders, American Psychiatric Association, Arlington, Va, USA, 5th edition, 2013.

[3] J. T. Becker, L. Kingsley, J. Mullen et al., "Vascular risk factors, HIV serostatus, and cognitive dysfunction in gay and bisexual men," Neurology, vol. 73, no. 16, pp. 1292-1299, 2009.

[4] F. Bonnet, H. Amieva, F. Marquant et al., "Cognitive disorders in HIV-infected patients: are they HIV-related?” AIDS, vol. 27, no. 3, pp. 391-400, 2013.

[5] H. A. Crystal, J. Weedon, S. Holman et al., "Associations of cardiovascular variables and HAART with cognition in middle-aged HIV-infected and uninfected women," Journal of Neuro Virology, vol. 17, no. 5, pp. 469-476, 2011.

[6] K. A. Armah, K. McGinnis, J. Baker et al., "HIV status, burden of comorbid disease, and biomarkers of inflammation, altered coagulation, and monocyte activation," Clinical Infectious Diseases, vol. 55, no. 1, pp. 126-136, 2012.

[7] H. Crystal, I. Kleyman, K. Anastos et al., "Effects of hepatitis $c$ and hiv on cognition in women: data from the women's interagency HIV study," Journal of Acquired Immune Deficiency Syndromes, vol. 59, no. 2, pp. 149-154, 2012.

[8] V. Tozzi, P. Balestra, P. Lorenzini et al., "Prevalence and risk factors for human immunodeficiency virus-associated neurocognitive impairment, 1996 to 2002: results from an urban observational cohort," Journal of NeuroVirology, vol. 11, no. 3, pp. 265-273, 2005.

[9] K. Buchacz, R. K. Baker, F. J. Palella Jr. et al., "Disparities in prevalence of key chronic diseases by gender and race/ethnicity among antiretroviral-treated HIV-infected adults in the US," Antiviral Therapy, vol. 18, no. 1, pp. 65-75, 2013.

[10] J. L. Hamilton, A. M. Brickman, R. Lang et al., "Relationship between depressive symptoms and cognition in older, nondemented African Americans," Journal of the International Neuropsychological Society, vol. 20, no. 7, pp. 756-763, 2014.

[11] K. R. Robertson, M. Smurzynski, T. D. Parsons et al., "The prevalence and incidence of neurocognitive impairment in the HAART era," AIDS, vol. 21, no. 14, pp. 1915-1921, 2007.

[12] D. A. Byrd, R. P. Fellows, S. Morgello et al., "Neurocognitive impact of substance use in HIV infection," Journal of Acquired Immune Deficiency Syndromes, vol. 58, no. 2, pp. 154-162, 2011.

[13] S. Cañizares, M. Cherner, and R. J. Ellis, "HIV and aging: effects on the central nervous system," Seminars in Neurology, vol. 34, no. 1, pp. 27-34, 2014.

[14] L. G. Chan and C. S. Wong, "HIV-associated neurocognitive disorders-an issue of growing importance," Annals of the Academy of Medicine, Singapore, vol. 42, pp. 527-534, 2013.

[15] C. E. Gamaldo, A. Gamaldo, J. Creighton et al., "Evaluating sleep and cognition in HIV," Journal of Acquired Immune Deficiency Syndromes, vol. 63, no. 5, pp. 609-616, 2013.

[16] L. A. Cysique, K. Moffat, D. M. Moore et al., "HIV, vascular and aging injuries in the brain of clinically stable HIV-infected adults: a (1)H MRS Study," PLoS ONE, vol. 8, no. 4, Article ID e61738, 2013.

[17] G. Andreou, F. Vlachos, and K. Makanikas, "Effects of chronic obstructive pulmonary disease and obstructive sleep apnea on cognitive functions: evidence for a common nature," Sleep Disorders, vol. 2014, Article ID 768210, 18 pages, 2014.

[18] J.-A. Palma, E. Urrestarazu, and J. Iriarte, "Sleep loss as risk factor for neurologic disorders: a review," Sleep Medicine, vol. 14, no. 3, pp. 229-236, 2013. 
[19] B. Haring, X. Leng, J. Robinson et al., "Cardiovascular disease and cognitive decline in postmenopausal women: results from the Women's Health Initiative Memory Study," Journal of the American Heart Association, vol. 2, no. 6, Article ID e000369, 2013.

[20] B. C. Schneider, A. L. Gross, K. J. Bangen et al., "Association of vascular risk factors with cognition in a multiethnic sample," The Journals of Gerontology. Series B, Psychological Sciences and Social Sciences, 2014.

[21] M. A. Kling, J. Q. Trojanowski, D. A. Wolk, V. M. Y. Lee, and S. E. Arnold, "Vascular disease and dementias: paradigm shifts to drive research in new directions," Alzheimer's and Dementia, vol. 9, no. 1, pp. 76-92, 2013.

[22] P. Sachdev, R. Kalaria, J. O’Brien et al., "Diagnostic criteria for vascular cognitive disorders: a VASCOG statement," Alzheimer Disease \& Associated Disorders, vol. 28, no. 3, pp. 206-218, 2014.

[23] J. L. Marcus, W. A. Leyden, C. R. Chao et al., "HIV infection and incidence of ischemic stroke," AIDS, vol. 28, no. 13, pp. 1911-1919, 2014.

[24] K. A. Lee, C. Gay, C. J. Portillo et al., "Types of sleep problems in adults living with HIV/AIDS," Journal of Clinical Sleep Medicine, vol. 8, no. 1, pp. 67-75, 2012.

[25] H. Samji, A. Cescon, R. S. Hogg et al., "Closing the gap: increases in life expectancy among treated HIV-positive individuals in the United States and Canada," PLoS ONE, vol. 8, no. 12, Article ID e81355, 2013.

[26] V. A. Triant, H. Lee, C. Hadigan, and S. K. Grinspoon, "Increased acute myocardial infarction rates and cardiovascular risk factors among patients with human immunodeficiency virus disease," Journal of Clinical Endocrinology and Metabolism, vol. 92, no. 7, pp. 2506-2512, 2007.

[27] S. De Wit, C. A. Sabin, R. Weber et al., "Incidence and risk factors for new-onset diabetes in HIV-infected patients: the Data Collection on Adverse Events of Anti-HIV Drugs (D:A:D) study," Diabetes Care, vol. 31, no. 6, pp. 1224-1229, 2008.

[28] K. Samaras, "Prevalence and pathogenesis of diabetes mellitus in HIV-1 infection treated with combined antiretroviral therapy," Journal of Acquired Immune Deficiency Syndromes, vol. 50, no. 5, pp. 499-505, 2009.

[29] Mind Exchange Working Group, "Assessment, diagnosis, and treatment of HIV-associated neurocognitive disorder: a consensus report of the mind exchange program," Clinical Infectious Diseases, vol. 56, no. 7, pp. 1004-1017, 2013.

[30] V. M. Dotson, M. H. Kitner-Triolo, M. K. Evans, and A. B. Zonderman, "Effects of race and socioeconomic status on the relative influence of education and literacy on cognitive functioning," Journal of the International Neuropsychological Society, vol. 15, no. 4, pp. 580-589, 2009.

[31] J. J. Manly, C. Smith, H. A. Crystal et al., "Relationship of ethnicity, age, education, and reading level to speed and executive function among HIV+ and HIV- women: the Women's Interagency HIV Study (WIHS) Neurocognitive Substudy," Journal of Clinical and Experimental Neuropsychology, vol. 33, no. 8, pp. 853-863, 2011.

[32] J. J. Manly, S. W. Miller, R. K. Heaton et al., "The effect of African-American acculturation on neuropsychological test performance in normal and HIV-positive individuals. The HIV Neurobehavioral Research Center (HNRC) Group," Journal of the International Neuropsychological Society, vol. 4, no. 3, pp. 291-302, 1998.

[33] S. Cross, N. Önen, A. Gase, E. T. Overton, and B. M. Ances, "Identifying risk factors for $\mathrm{HIV}$-associated neurocognitive disorders using the international HIV dementia scale," Journal of Neuroimmune Pharmacology, vol. 8, no. 5, pp. 1114-1122, 2013.

[34] J. Kamminga, L. A. Cysique, G. Lu, J. Batchelor, and B. J. Brew, "Validity of cognitive screens for HIV-associated neurocognitive disorder: a systematic review and an informed screen selection guide," Current HIV/AIDS Reports, vol. 10, no. 4, pp. 342-355, 2013.

[35] K. Robertson and S. Yosief, "Neurocognitive assessment in the diagnosis of HIV-associated neurocognitive disorders," Seminars in Neurology, vol. 34, no. 1, pp. 21-26, 2014.

[36] V. Valcour, R. Paul, S. Chiao, L. A. Wendelken, and B. Miller, "Screening for cognitive impairment in human immunodeficiency virus," Clinical Infectious Diseases, vol. 53, no. 8, pp. 836842, 2011.

[37] M. A. Richardson, E. E. Morgan, M. J. Vielhauer, C. A. Cuevas, L. M. Buondonno, and T. M. Keane, "Utility of the HIV dementia scale in assessing risk for significant HIV-related cognitive-motor deficits in a high-risk urban adult sample," AIDS Care, vol. 17, no. 8, pp. 1013-1021, 2005.

[38] V. Wojna, R. L. Skolasky, J. C. McArthur et al., "Spanish validation of the HIV dementia scale in women," AIDS Patient Care and STDs, vol. 21, no. 12, pp. 930-941, 2007.

[39] S. P. Woods, J. D. Rippeth, A. B. Frol et al., "Interrater reliability of clinical ratings and neurocognitive diagnoses in HIV," Journal of Clinical and Experimental Neuropsychology, vol. 26, no. 6, pp. 759-778, 2004.

[40] K. Goodkin, F. L. Wilkie, M. Concha et al., "Aging and neuroAIDS conditions and the changing spectrum of HIV-1-associated morbidity and mortality," Journal of Clinical Epidemiology, vol. 54, no. 12, supplement 1, pp. S35-S43, 2001.

[41] N. Sacktor, M. P. McDermott, K. Marder et al., "HIV-associated cognitive impairment before and after the advent of combination therapy," Journal of Neuro Virology, vol. 8, no. 2, pp. 136-142, 2002.

[42] R. K. Heaton, D. R. Franklin, R. J. Ellis et al., "HIV-associated neurocognitive disorders before and during the era of combination antiretroviral therapy: differences in rates, nature, and predictors," Journal of Neuro Virology, vol. 17, no. 1, pp. 3-16, 2011.

[43] J. C. McArthur, J. Steiner, N. Sacktor, and A. Nath, "Human immunodeficiency virus-associated neurocognitive disorders mind the gap," Annals of Neurology, vol. 67, no. 6, pp. 699-714, 2010.

[44] P. Gannon, M. Z. Khan, and D. L. Kolson, "Current understanding of HIV-associated neurocognitive disorders pathogenesis," Current Opinion in Neurology, vol. 24, no. 3, pp. 275-283, 2011.

[45] D. B. Clifford and B. M. Ances, "HIV-associated neurocognitive disorder," The Lancet Infectious Diseases, vol. 13, no. 11, pp. 976986, 2013.

[46] R. K. Heaton, D. B. Clifford, D. R. Franklin et al., "HIV-associated neurocognitive disorders persist in the era of potent antiretroviral therapy: Charter Study," Neurology, vol. 75, no. 23, pp. 2087-2096, 2010.

[47] A. R. Zipursky, D. Gogolishvili, S. Rueda et al., "Evaluation of brief screening tools for neurocognitive impairment in HIV/AIDS: a systematic review of the literature," AIDS, vol. 27, no. 15, pp. 2385-2401, 2013.

[48] E. Cassol, V. Misra, S. Morgello, and D. Gabuzda, "Applications and limitations of inflammatory biomarkers for studies on neurocognitive impairment in HIV infection," Journal of Neuroimmune Pharmacology, vol. 8, no. 5, pp. 1087-1097, 2013. 
[49] K. Blackstone, D. J. Moore, R. K. Heaton et al., "Diagnosing symptomatic HIV-associated neurocognitive disorders: selfreport versus performance-based assessment of everyday functioning," Journal of the International Neuropsychological Society, vol. 18, no. 1, pp. 79-88, 2012.

[50] B. M. Ances and D. B. Clifford, "HIV-associated neurocognitive disorders and the impact of combination antiretroviral therapies," Current Neurology and Neuroscience Reports, vol. 8, no. 6, pp. 455-461, 2008.

[51] E. T. Overton, J. S. Kauwe, R. Paul et al., "Performances on the cogstate and standard neuropsychological batteries among HIV patients without dementia," AIDS and Behavior, vol. 15, no. 8, pp. 1902-1909, 2011.

[52] B. Milanini, L. A. Wendelken, P. Esmaeili-Firidouni, M. Chartier, P. C. Crouch, and V. Valcour, "The montreal cognitive assessment (MOCA) to screen for cognitive impairment in HIV over age 60," Journal of Acquired Immune Deficiency Syndromes, 2014.

[53] R. J. Ellis, S. R. Evans, D. B. Clifford et al., "Clinical validation of the NeuroScreen," Journal of NeuroVirology, vol. 11, no. 6, pp. 503-511, 2005.

[54] R. N. Robbins, H. Brown, A. Ehlers et al., "A smartphone app to screen for HIV-related neurocognitive impairment," Journal of Mobile Technology in Medicine, vol. 3, no. 1, pp. 23-26, 2014.

[55] L. J. Haddow, S. Floyd, A. Copas, and R. J. C. Gilson, "A systematic review of the screening accuracy of the HIV dementia scale and international HIV dementia scale," PLoS ONE, vol. 8, no. 4, Article ID e61826, 2013.

[56] L. S. Rosenthal, R. L. Skolasky, R. T. Moxley IV et al., "A novel computerized functional assessment for human immunodeficiency virus-associated neurocognitive disorder," Journal of NeuroVirology, vol. 19, no. 5, pp. 432-441, 2013.

[57] P. Desplats, W. Dumaop, D. Smith et al., "Molecular and pathologic insights from latent HIV-1 infection in the human brain," Neurology, vol. 80, no. 15, pp. 1415-1423, 2013.

[58] W. Li, G. Li, J. Steiner, and A. Nath, "Role of Tat protein in HIV neuropathogenesis," Neurotoxicity Research, vol. 16, no. 3, pp. 205-220, 2009.

[59] V. R. Rao, A. P. Ruiz, and V. R. Prasad, "Viral and cellular factors underlying neuropathogenesis in HIV associated neurocognitive disorders (HAND)," AIDS Research and Therapy, vol. 11, no. 1, article 13, 2014.

[60] A. J. Gill and D. L. Kolson, "Chronic inflammation and the role for cofactors (hepatitis $\mathrm{C}$, drug abuse, antiretroviral drug toxicity, aging) in HAND persistence," Current HIV/AIDS Reports, vol. 11, no. 3, pp. 325-335, 2014.

[61] B. J. Brew and P. Chan, "Update on HIV dementia and HIVassociated neurocognitive disorders," Current Neurology and Neuroscience Reports, vol. 14, no. 8, article 468, 2014.

[62] L. Qin, X. Wu, M. L. Block et al., "Systemic LPS causes chronic neuroinflammation and progressive neurodegeneration," Glia, vol. 55, no. 5, pp. 453-462, 2007.

[63] E. Tavazzi, D. Morrison, P. Sullivan, S. Morgello, and T. Fischer, "Brain inflammation is a common feature of HIVinfected patients without HIV encephalitis or productive brain infection," Current HIV Research, vol. 12, no. 2, pp. 97-110, 2014.

[64] P. Chan and B. J. Brew, "HIV associated neurocognitive disorders in the modern antiviral treatment era: prevalence, characteristics, biomarkers, and effects of treatment," Current HIV/ AIDS Reports, vol. 11, no. 3, pp. 317-324, 2014.
[65] M. Cherner, S. Letendre, R. K. Heaton et al., "Hepatitis C augments cognitive deficits associated with HIV infection and methamphetamine," Neurology, vol. 64, no. 8, pp. 1343-1347, 2005.

[66] R. S. Durvasula and C. H. Hinkin, "Neuropsychological dysfunction among HIV infected drug abusers," American Journal of Infectious Diseases, vol. 2, no. 2, pp. 67-73, 2006.

[67] N. Ciccarelli, M. Fabbiani, P. Grima et al., "Comparison of cognitive performance in HIV or HCV mono-infected and HIV-HCV co-infected patients," Infection, vol. 41, no. 6, pp. 1103-1109, 2013.

[68] R. P. Fellows, D. A. Byrd, and S. Morgello, "Major depressive disorder, cognitive symptoms, and neuropsychological performance among ethnically diverse HIV+ men and women," Journal of the International Neuropsychological Society, vol. 19, no. 2, pp. 216-225, 2013.

[69] R. M. Fialho, M. Pereira, N. Mendonça, and S. Ouakinin, "Depressive symptoms and neurocognitive performance among HIV-infected women," Women and Health, vol. 53, no. 2, pp. 117-134, 2013.

[70] C. H. Hinkin, S. A. Castellon, A. J. Levine, T. R. Barclay, and E. J. Singer, "Neurocognition in individuals co-infected with HIV and hepatitis C," Journal of Addictive Diseases, vol. 27, no. 2, pp. $11-17,2008$.

[71] K. Lin, M. J. Taylor, R. Heaton et al., "Effects of traumatic brain injury on cognitive functioning and cerebral metabolites in HIV-infected individuals," Journal of Clinical and Experimental Neuropsychology, vol. 33, no. 3, pp. 326-334, 2011.

[72] M. Mapstone, T. N. Hilton, H. Yang et al., "Poor aerobic fitness may contribute to cognitive decline in HIV-infected older adults," Aging and Disease, vol. 4, no. 6, pp. 311-319, 2013.

[73] V. G. Valcour, N. C. Sacktor, R. H. Paul et al., "Insulin resistance is associated with cognition among HIV-1-infected patients: the Hawaii aging with HIV cohort," Journal of Acquired Immune Deficiency Syndromes, vol. 43, no. 4, pp. 405-410, 2006.

[74] K. Harkness, C. Demers, G. A. Heckman, and R. S. McKelvie, "Screening for cognitive deficits using the montreal cognitive assessment tool in outpatients $\geq 65$ years of age with heart failure," The American Journal of Cardiology, vol. 107, no. 8, pp. 1203-1207, 2011.

[75] A. J. Larner, "Screening utility of the montreal cognitive assessment (MoCA): in place of-or as well as-the MMSE?" International Psychogeriatrics, vol. 24, no. 3, pp. 391-396, 2012.

[76] K. A. Bottiggi, J. J. Chang, F. A. Schmitt et al., “The HIV Dementia Scale: predictive power in mild dementia and HAART," Journal of the Neurological Sciences, vol. 260, no. 1-2, pp. 11-15, 2007.

[77] G. D. Lopardo, E. Bissio, M. D. C. Iannella, A. D. Crespo, D. B. Garone, and L. I. Cassetti, "Good neurocognitive performance measured by the international HIV dementia scale in early HIV1 infection," Journal of Acquired Immune Deficiency Syndromes, vol. 52, no. 4, pp. 488-492, 2009.

[78] L. A. J. Cysique, P. Maruff, D. Darby, and B. J. Brew, “The assessment of cognitive function in advanced HIV-1 infection and AIDS dementia complex using a new computerised cognitive test battery," Archives of Clinical Neuropsychology, vol. 21, no. 2, pp. 185-194, 2006.

[79] P. M. Maki and E. Martin-Thormeyer, "HIV, Cognition and Women," Neuropsychology Review, vol. 19, no. 2, pp. 204-214, 2009.

[80] A. C. Justice, K. A. McGinnis, J. H. Atkinson et al., "Psychiatric and neurocognitive disorders among HIV-positive and negative 
veterans in care: veterans Aging Cohort Five-Site Study," AIDS, vol. 18, supplement 1, pp. S49-S59, 2004.

[81] D. A. Byrd, J. Robinson-Papp, M. R. Mindt et al., "Isolating cognitive and neurologic HIV effects in substance-dependent, confounded cohorts: a pilot study," Journal of the International Neuropsychological Society, vol. 19, no. 4, pp. 463-473, 2013.

[82] J. McDonnell, L. Haddow, M. Daskalopoulou et al., "Minimal cognitive impairment in UK HIV positive men who have sex with men: effect of case definitions, and comparison with the general population and HIV negative men," Journal of Acquired Immune Deficiency Syndromes, vol. 67, no. 2, pp. 120-127, 2014.

[83] S. M. Patel, A. D. Thames, N. Arbid, S. E. Panos, S. Castellon, and C. H. Hinkin, "The aggregate effects of multiple comorbid risk factors on cognition among HIV-infected individuals," Journal of Clinical and Experimental Neuropsychology, vol. 35, no. 4, pp. 421-434, 2013.

[84] S. Byrne and N. M. Petry, "Reliability and validity of the Functional Assessment of Human Immunodeficiency Virus Infection (FAHI) in patients with drug and alcohol use disorders," AIDS Care-Psychological and Socio-Medical Aspects of AIDS/ HIV, vol. 25, no. 1, pp. 118-125, 2013.

[85] K. Erlandson, A. Allshouse, C. Jankowski et al., "Comparison of functional status instruments in HIV-infected adults on effective antiretroviral therapy," HIV Clinical Trials, vol. 13, no. 6, pp. 324-334, 2012.

[86] N. S. Gandhi, R. L. Skolasky, K. B. Peters et al., "A comparison of performance-based measures of function in HIV-associated neurocognitive disorders," Journal of NeuroVirology, vol. 17, no. 2, pp. 159-165, 2011.

[87] M. Viala-Danten, D. Dubois, H. Gilet, S. Martin, K. Peeters, and D. Cella, "Psychometric evaluation of the functional assessment of HIV infection (FAHI) questionnaire and its usefulness in clinical trials," Quality of Life Research, vol. 19, no. 8, pp. 12151227, 2010.

[88] A. L. Jefferson, L. E. Gibbons, D. M. Rentz et al., "A life course model of cognitive activities, socioeconomic status, education, reading ability, and cognition," Journal of the American Geriatrics Society, vol. 59, no. 8, pp. 1403-1411, 2011.

[89] L. C. Bernard, "Halstead-Reitan Neuropsychological Test performance of black, hispanic, and white young adult males from poor academic backgrounds," Archives of Clinical Neuropsychology, vol. 4, no. 3, pp. 267-274, 1989.

[90] B. J. Gurland, D. E. Wilder, P. Cross, J. Teresi, and V. W. Barrett, "Screening scales for dementia: toward reconciliation of conflicting cross-cultural findings," International Journal of Geriatric Psychiatry, vol. 7, no. 2, pp. 105-113, 1992.

[91] J. J. Manly, D. M. Jacobs, M. Sano et al., "Cognitive test performance among nondemented elderly African Americans and whites," Neurology, vol. 50, no. 5, pp. 1238-1245, 1998.

[92] A. Ardila, M. Rosselli, and P. Rosas, "Neuropsychological assessment in illiterates: visuospatial and memory abilities," Brain and Cognition, vol. 11, no. 2, pp. 147-166, 1989.

[93] J. J. Manly, P. Touradji, M.-X. Tang, and Y. Stern, "Literacy and memory decline among ethnically diverse elders," Journal of Clinical and Experimental Neuropsychology, vol. 25, no. 5, pp. 680-690, 2003.

[94] A. Ardila, F. Ostrosky-Solis, M. Rosselli, and C. Gómez, "Agerelated cognitive decline during normal aging: the complex effect of education," Archives of Clinical Neuropsychology, vol. 15, no. 6, pp. 495-513, 2000 .

[95] V. M. Dotson, M. Kitner-Triolo, M. K. Evans, and A. B. Zonderman, "Literacy-based normative data for low socioeconomic status African Americans," Clinical Neuropsychologist, vol. 22, no. 6, pp. 989-1017, 2008.

[96] E. L. Ryan, R. Baird, M. R. Mindt, D. Byrd, J. Monzones, and S. Morgello, "Neuropsychological impairment in racial/ethnic minorities with HIV infection and low literacy levels: effects of education and reading level in participant characterization," Journal of the International Neuropsychological Society, vol. 11, no. 7, pp. 889-898, 2005.

[97] M. Rohit, A. Levine, C. Hinkin et al., "Education correction using years in school or reading grade-level equivalent? Comparing the accuracy of two methods in diagnosing HIV-associated neurocognitive impairment," Journal of the International Neuropsychological Society, vol. 13, no. 3, pp. 462-470, 2007.

[98] J. Leserman, K. Whetten, K. Lowe, D. Stangl, M. S. Swartz, and N. M. Thielman, "How trauma, recent stressful events, and PTSD affect functional health status and health utilization in HIV-infected patients in the South," Psychosomatic Medicine, vol. 67, no. 3, pp. 500-507, 2005.

[99] G. Spies, C. Fennema-Notestine, S. L. Archibald, M. Cherner, and S. Seedat, "Neurocognitive deficits in HIV-infected women and victims of childhood trauma," AIDS Care, vol. 24, no. 9, pp. 1126-1135, 2012.

[100] Z. C. E. Troeman, G. Spies, M. Cherner et al., "Impact of childhood trauma on functionality and quality of life in HIV-infected women," Health and Quality of Life Outcomes, vol. 9, article 84, 2011.

[101] D. E. Vance, P. L. Fazeli, L. Moneyham, N. L. Keltner, and J. L. Raper, "Assessing and treating forgetfulness and cognitive problems in adults with HIV," Journal of the Association of Nurses in AIDS Care, vol. 24, no. 1, pp. S40-S60, 2013.

[102] D. E. Vance, P. L. Fazeli, J. S. Grant, L. Z. Slater, and J. L. Raper, "The role of neuroplasticity and cognitive reserve in aging with HIV: recommendations for cognitive protection and rehabilitation," Journal of Neuroscience Nursing, vol. 45, no. 5, pp. 306-316, 2013.

[103] J. Foley, M. Ettenhofer, M. J. Wright et al., "Neurocognitive functioning in HIV-1 infection: effects of cerebrovascular risk factors and age," Clinical Neuropsychologist, vol. 24, no. 2, pp. 265-285, 2010.

[104] P. Satz, H. Morgenstern, E. N. Miller et al., "Low education as a possible risk factor for cognitive abnormalities in HIV1: findings from the multicenter AIDS cohort study (MACS)," Journal of Acquired Immune Deficiency Syndromes, vol. 6, no. 5, pp. 503-511, 1993.

[105] G. W. Evans and M. A. Schamberg, "Childhood poverty, chronic stress, and adult working memory," Proceedings of the National Academy of Sciences of the United States of America, vol. 106, no. 16, pp. 6545-6549, 2009.

[106] J. S. Tucker, S. L. Wenzel, M. N. Elliott, G. N. Marshall, and S. Williamson, "Interpersonal violence, substance use, and HIVrelated behavior and cognitions: a prospective study of impoverished women in Los Angeles County," AIDS and Behavior, vol. 8, no. 4, pp. 463-474, 2004.

[107] D. E. Vance, J. Randazza, S. Fogger, L. Z. Slater, S. C. Humphrey, and N. L. Keltner, "An overview of the biological and psychosocial context surrounding neurocognition in HIV," Journal of the American Psychiatric Nurses Association, vol. 20, no. 2, pp. 117124, 2014.

[108] O. L. Lopez, L. H. Kuller, J. T. Becker et al., "Classification of vascular dementia in the Cardiovascular Health Study Cognition Study," Neurology, vol. 64, no. 9, pp. 1539-1547, 2005. 
[109] K. Yaffe, E. Vittinghoff, M. J. Pletcher et al., "Early adult to midlife cardiovascular risk factors and cognitive function," Circulation, vol. 129, no. 15, pp. 1560-1567, 2014.

[110] M. S. Beeri, R. Ravona-Springer, J. M. Silverman, and V. Haroutunian, "The effects of cardiovascular risk factors on cognitive compromise," Dialogues in Clinical Neuroscience, vol. 11, no. 2, pp. 201-212, 2009.

[111] T. E. Gildner, M. A. Liebert, P. Kowal, S. Chatterji, and J. J. Snodgrass, "Associations between sleep duration, sleep quality, and cognitive test performance among older adults from six middle income countries: results from the Study on Global Ageing and Adult Health (SAGE)," Journal of Clinical Sleep Medicine, vol. 10, no. 6, pp. 613-621, 2014.

[112] M. L. Jackson, M. E. Howard, and M. Barnes, "Cognition and daytime functioning in sleep-related breathing disorders," Progress in Brain Research, vol. 190, pp. 53-68, 2011.

[113] D. M. Forton, S. D. Taylor-Robinson, and H. C. Thomas, "Cerebral dysfunction in chronic hepatitis C infection," Journal of Viral Hepatitis, vol. 10, no. 2, pp. 81-86, 2003.

[114] S. P. Kennelly, "Cognitive dysfunction: an important extrahepatic manifestation of hepatitis C infection?" Postgraduate Medical Journal, vol. 89, no. 1054, pp. 431-432, 2013.

[115] J. S. Lin, E. O'Connor, R. C. Rossom et al., "U.S. Preventive Services Task Force evidence syntheses, formerly systematic evidence reviews," in Screening for Cognitive Impairment in Older Adults: An Evidence Update for the U.S. Preventive Services Task Force, Agency for Healthcare Research and Quality (US), Rockville, Md, USA, 2013.

[116] C. f. D. C. a. Prevention, HIV Surveillance Supplemental Report, vol. 18, C. f. D. C. a. Prevention, 2013.

[117] N. Wada, L. P. Jacobson, M. Cohen, A. French, J. Phair, and A. Muñoz, "Cause-specific life expectancies after 35 years of age for human immunodeficiency syndrome-infected and human immunodeficiency syndrome-negative individuals followed simultaneously in long-term cohort studies, 1984-2008," American Journal of Epidemiology, vol. 177, no. 2, pp. 116-125, 2013.

[118] V. Valcour, C. Shikuma, B. Shiramizu et al., "Higher frequency of dementia in older HIV-1 individuals: the Hawaii aging with HIV-1 cohort," Neurology, vol. 63, no. 5, pp. 822-827, 2004.

[119] V. G. Valcour, C. M. Shikuma, M. R. Watters, and N. C. Sacktor, "Cognitive impairment in older HIV-1-seropositive individuals: prevalence and potential mechanisms," AIDS, vol. 18, supplement 1, pp. S79-S86, 2004.

[120] R. B. Effros, C. V. Fletcher, K. Gebo et al., "Workshop on HIV infection and aging: What is known and future research directions," Clinical Infectious Diseases, vol. 47, no. 4, pp. 542-553, 2008.

[121] J. T. Becker, O. L. Lopez, M. A. Dew, and H. J. Aizenstein, "Prevalence of cognitive disorders differs as a function of age in HIV virus infection," AIDS, vol. 18, supplement 1, pp. S11-S18, 2004.

[122] G. C. Román, P. Sachdev, D. R. Royall et al., "Vascular cognitive disorder: a new diagnostic category updating vascular cognitive impairment and vascular dementia," Journal of the Neurological Sciences, vol. 226, no. 1-2, pp. 81-87, 2004.

[123] P. B. Gorelick, A. Scuteri, S. E. Black et al., "Vascular contributions to cognitive impairment and dementia: a statement for healthcare professionals from the American Heart Association/American Stroke Association," Stroke, vol. 42, no. 9, pp. 2672-2713, 2011.

[124] F. C. Chow, "HIV infection, vascular disease, and stroke," Seminars in Neurology, vol. 34, no. 1, pp. 35-46, 2014.
[125] D. A. Duprez, J. Neuhaus, L. H. Kuller et al., "Inflammation, coagulation and cardiovascular disease in HIV-infected individuals," PloS ONE, vol. 7, no. 9, Article ID e44454, 2012.

[126] P. Y. Hsue, R. Scherzer, P. W. Hunt et al., "Carotid intimamedia thickness progression in HIV-infected adults occurs preferentially at the carotid bifurcation and is predicted by inflammation," Journal of the American Heart Association, vol. 1, no. 2, 2012.

[127] J. V. Baker and D. Duprez, "Biomarkers and HIV-associated cardiovascular disease," Current Opinion in HIV and AIDS, vol. 5, no. 6, pp. 511-516, 2010.

[128] P. Tebas, "Insulin resistance and diabetes mellitus associated with antiretroviral use in HIV-infected patients: pathogenesis, prevention, and treatment options," Journal of Acquired Immune Deficiency Syndromes, vol. 49, supplement 2, pp. S86-S92, 2008.

[129] P. P. Filardi, S. Paolillo, C. Marciano et al., "Cardiovascular effects of antiretroviral drugs: clinical review," Cardiovascular and Hematological Disorders-Drug Targets, vol. 8, no. 4, pp. 238-244, 2008.

[130] M. W. Lorenz, C. Stephan, A. Harmjanz et al., "Both longterm HIV infection and highly active antiretroviral therapy are independent risk factors for early carotid atherosclerosis," Atherosclerosis, vol. 196, no. 2, pp. 720-726, 2008.

[131] M. Calvo and E. Martinez, "Update on metabolic issues in HIV patients," Current Opinion in HIV and AIDS, vol. 9, pp. 332-339, 2014.

[132] S. Rahmanian, M. E. Wewers, S. Koletar, N. Reynolds, A. Ferketich, and P. Diaz, "Cigarette smoking in the hiv-infected population," Proceedings of the American Thoracic Society, vol. 8, no. 3, pp. 313-319, 2011.

[133] M. Fabbiani, N. Ciccarelli, M. Tana et al., "Cardiovascular risk factors and carotid intima-media thickness are associated with lower cognitive performance in HIV-infected patients," HIV Medicine, vol. 14, no. 3, pp. 136-144, 2013.

[134] J. Foley, M. Ettenhofer, M. Wright, and C. H. Hinkin, "Emerging issues in the neuropsychology of HIV infection," Current HIV/AIDS Reports, vol. 5, no. 4, pp. 204-211, 2008.

[135] E. J. Wright, B. Grund, K. Robertson et al., "Cardiovascular risk factors associated with lower baseline cognitive performance in HIV-positive persons," Neurology, vol. 75, no. 10, pp. 864-873, 2010.

[136] A. K. Kurian and K. M. Cardarelli, "Racial and ethnic differences in cardiovascular disease risk factors: a systematic review," Ethnicity and Disease, vol. 17, no. 1, pp. 143-152, 2007.

[137] S. K. Davis, S. Gebreab, R. Quarells, and G. H. Gibbons, "Social determinants of cardiovascular health among black and white women residing in stroke belt and buckle regions of the South," Ethnicity \& Disease, vol. 24, no. 2, pp. 133-143, 2014.

[138] C. U. Oramasionwu, J. M. Hunter, C. M. Brown et al., "Cardiovascular disease in blacks with HIV/AIDS in the united States: a systematic review of the Literature," Open AIDS Journal, vol. 6, no. 1, pp. 29-35, 2012.

[139] K. N. Althoff, K. A. Gebo, S. J. Gange et al., "CD4 count at presentation for HIV care in the United States and Canada: are those over 50 years more likely to have a delayed presentation?" AIDS Research and Therapy, vol. 7, article 45, 2010.

[140] Y. O. Whiteside, S. M. Cohen, H. Bradley, J. Skarbinski, H. I. Hall, and A. Lansky, "Progress along the continuum of HIV care among blacks with diagnosed HIV-United States, 2010," Morbidity and Mortality Weekly Report, vol. 63, no. 5, pp. 8589, 2014. 
[141] H. I. Hall, E. L. Frazier, P. Rhodes et al., "Differences in human immunodeficiency virus care and treatment among subpopulations in the United States," JAMA Internal Medicine, vol. 173, no. 14, pp. 1337-1344, 2013.

[142] S. Reid and J. Dwyer, "Insomnia in HIV infection: a systematic review of prevalence, correlates, and management," Psychosomatic Medicine, vol. 67, no. 2, pp. 260-269, 2005.

[143] G. Jean-Louis, K. M. Weber, B. E. Aouizerat et al., "Insomnia symptoms and HIV infection among participants in the women's interagency HIV study," Sleep, vol. 35, no. 1, pp. 131137, 2012.

[144] L. J. Epstein, P. J. Strollo Jr., R. B. Donegan, J. Delmar, C. Hendrix, and P. R. Westbrook, "Obstructive sleep apnea in patients with human immunodeficiency virus (HIV) disease," Sleep, vol. 18, no. 5, pp. 368-376, 1995.

[145] N. F. Crum-Cianflone, M. P. Roediger, D. J. Moore et al., "Prevalence and factors associated with sleep disturbances among early-treated HIV-infected persons," Clinical Infectious Diseases, vol. 54, no. 10, pp. 1485-1494, 2012.

[146] D. M. Taibi, "Sleep Disturbances in Persons Living With HIV," Journal of the Association of Nurses in AIDS Care, vol. 24, pp. S72-S85, 2013.

[147] E. H. Decloedt and G. Maartens, "Neuronal toxicity of efavirenz: a systematic review," Expert Opinion on Drug Safety, vol. 12, no. 6, pp. 841-846, 2013.

[148] N. T. Ayas, D. P. White, J. E. Manson et al., "A prospective study of sleep duration and coronary heart disease in women," Archives of Internal Medicine, vol. 163, no. 2, pp. 205-209, 2003.

[149] C. M. Depner, E. R. Stothard, and K. P. Wright Jr., "Metabolic consequences of sleep and circadian disorders," Current Diabetes Reports, vol. 14, no. 7, 2014.

[150] L. F. Drager, S. M. Togeiro, V. Y. Polotsky, and G. Lorenzi-Filho, "Obstructive sleep apnea: a cardiometabolic risk in obesity and the metabolic syndrome," Journal of the American College of Cardiology, vol. 62, no. 7, pp. 569-576, 2013.

[151] M. A. Grandner, N. J. Jackson, V. M. Pak, and P. R. Gehrman, "Sleep disturbance is associated with cardiovascular and metabolic disorders," Journal of Sleep Research, vol. 21, no. 4, pp. 427433, 2012.

[152] H. R. Javadi, S. Jalilolghadr, Z. Yazdi, and Z. R. Majd, "Correlation between obstructive sleep apnea syndrome and cardiac disease severity," Cardiovascular Psychiatry and Neurology, vol. 2014, Article ID 631380, 5 pages, 2014.

[153] J. P. Morano, B. A. Gibson, and F. L. Altice, “The burgeoning HIV/HCV syndemic in the urban Northeast: HCV, HIV, and HIV/HCV coinfection in an urban setting," PLoS ONE, vol. 8, no. 5, Article ID e64321, 2013.

[154] P. Gupta, "Hepatitis C virus and HIV type 1 co-infection," Infectious Disease Reports, vol. 5, no. 1S, p. 7, 2013.

[155] M. S. Sulkowski, "Hepatitis C virus infection in HIV-infected patients," Current Infectious Disease Reports, vol. 3, no. 5, pp. 469-476, 2007.

[156] L. J. Garvey, N. Pavese, A. Ramlackhansingh et al., "Acute $\mathrm{HCV} / \mathrm{HIV}$ coinfection is associated with cognitive dysfunction and cerebral metabolite disturbance, but not increased microglial cell activation," PLoS ONE, vol. 7, no. 7, Article ID e38980, 2012.

[157] E. L. Ryan, S. Morgello, K. Isaacs, M. Naseer, and P. Gerits, "Neuropsychiatric impact of hepatitis C on advanced HIV," Neurology, vol. 62, no. 6, pp. 957-962, 2004.
[158] J. L. Richardson, M. Nowicki, K. Danley et al., "Neuropsychological functioning in a cohort of HIV- and hepatitis C virusinfected women," AIDS, vol. 19, no. 15, pp. 1659-1667, 2005.

[159] D. B. Clifford, F. Vaida, Y.-T. Kao et al., "Absence of neurocognitive effect of hepatitis C infection in HIV-coinfected people," Neurology, vol. 84, no. 3, pp. 241-250, 2015.

[160] V. Byrnes, A. Miller, D. Lowry et al., "Effects of anti-viral therapy and HCV clearance on cerebral metabolism and cognition," Journal of Hepatology, vol. 56, no. 3, pp. 549-556, 2012.

[161] R. M. Schuster and R. Gonzalez, "Substance abuse, hepatitis C, and aging in HIV: common cofactors that contribute to neurobehavioral disturbances," Neurobehavioral HIV Medicine, vol. 4, no. 1, pp. 15-34, 2012.

[162] R. Gonzalez, R. M. Schuster, J. Vassileva, and E. M. Martin, "Impact of HIV and a history of marijuana dependence on procedural learning among individuals with a history of substance dependence," Journal of Clinical and Experimental Neuropsychology, vol. 33, no. 7, pp. 735-752, 2011.

[163] A. Nath, "Human immunodeficiency virus-associated neurocognitive disorder: pathophysiology in relation to drug addiction," Annals of the New York Academy of Sciences, vol. 1187, pp. 122-128, 2010.

[164] K. F. Corsi and R. E. Booth, "HIV sex risk behaviors among heterosexual methamphetamine users: literature review from 2000 to present," Current Drug Abuse Reviews, vol. 1, no. 3, pp. 292-296, 2008.

[165] R. S. Durvasula, H. F. Myers, K. Mason, and C. Hinkin, "Relationship between alcohol use/abuse, HIV infection and neuropsychological performance in African American men," Journal of Clinical and Experimental Neuropsychology, vol. 28, no. 3, pp. 383-404, 2006.

[166] S. Buch, H. Yao, M. Guo et al., "Cocaine and HIV-1 interplay in CNS: cellular and molecular mechanisms," Current HIV Research, vol. 10, no. 5, pp. 425-428, 2012.

[167] P. J. Gaskill, T. M. Calderon, J. S. Coley, and J. W. Berman, "Drug induced increases in CNS dopamine alter monocyte, macrophage and T cell functions: implications for HAND," Journal of Neuroimmune Pharmacology, vol. 8, no. 3, pp. 621642, 2013.

[168] V. Purohit, R. Rapaka, and D. Shurtleff, "Drugs of abuse, dopamine, and HIV-associated neurocognitive disorders/HIVassociated dementia," Molecular Neurobiology, vol. 44, no. 1, pp. 102-110, 2011.

[169] P. S. Silverstein, A. Shah, J. Weemhoff, S. Kumar, D. P. Singh, and A. Kumar, "HIV-1 gp120 and drugs of abuse: interactions in the central nervous system," Current HIV Research, vol. 10, no. 5, pp. 369-383, 2012.

[170] M. M. Jacobs, J. Murray, D. A. Byrd, Y. L. Hurd, and S. Morgello, "HIV-related cognitive impairment shows bi-directional association with dopamine receptor DRD1 and DRD2 polymorphisms in substance-dependent and substance-independent populations," Journal of Neuro Virology, vol. 19, no. 5, pp. 495504, 2013.

[171] C. H. Hinkin, D. J. Hardy, K. I. Mason et al., "Medication adherence in HIV-infected adults: effect of patient age, cognitive status, and substance abuse," AIDS, vol. 18, no. 1, pp. S19-S25, 2004.

[172] D. J. Moore, K. Blackstone, S. P. Woods et al., "Methamphetamine use and neuropsychiatric factors are associated with antiretroviral non-adherence," AIDS Care, vol. 24, no. 12, pp. 1504-1513, 2012. 
[173] D. Waldrop-Valverde, R. L. Ownby, F. L. Wilkie, A. MacK, M. Kumar, and L. Metsch, "Neurocognitive aspects of medication adherence in HIV-positive injecting drug users," AIDS and Behavior, vol. 10, no. 3, pp. 287-297, 2006.

[174] J. H. Atkinson, R. K. Heaton, T. L. Patterson et al., "Two-year prospective study of major depressive disorder in HIV-infected men," Journal of Affective Disorders, vol. 108, no. 3, pp. 225-234, 2008.

[175] T. Benton, J. Staab, and D. L. Evans, "Medical co-morbidity in depressive disorders," Annals of Clinical Psychiatry, vol. 19, no. 4, pp. 289-303, 2007.

[176] A. N. Do, E. S. Rosenberg, P. S. Sullivan et al., "Excess burden of depression among HIV-infected persons receiving medical care in the United States: data from the medical monitoring project and the behavioral risk factor surveillance system," PLOS ONE, vol. 9, no. 3, Article ID e92842, 2014.

[177] T. Gibbie, A. Mijch, S. Ellen et al., "Depression and neurocognitive performance in individuals with HIV/AIDS: 2-year followup," HIV Medicine, vol. 7, no. 2, pp. 112-121, 2006.

[178] M. F. Morrison, J. M. Petitto, T. Ten Have et al., "Depressive and anxiety disorders in women with HIV infection," The American Journal of Psychiatry, vol. 159, no. 5, pp. 789-796, 2002.

[179] A. D. Thames, J. Moizel, S. E. Panos et al., "Differential predictors of medication adherence in HIV: findings from a sample of African American and caucasian HIV-positive drug-using adults," AIDS Patient Care and STDs, vol. 26, no. 10, pp. 621630, 2012.

[180] J. R. Ickovics, M. E. Hamburger, D. Vlahov et al., "Mortality, CD4 cell count decline, and depressive symptoms among HIV-seropositive women: longitudinal analysis from the HIV epidemiology research study," Journal of the American Medical Association, vol. 285, no. 11, pp. 1466-1474, 2001.

[181] K. Kroenke, R. L. Spitzer, and J. B. W. Williams, “The patient health questionnaire-2: validity of a two-item depression screener," Medical Care, vol. 41, no. 11, pp. 1284-1292, 2003.

[182] W. Zhang, N. O’Brien, J. I. Forrest et al., "Validating a shortened depression scale (10 item CES-D) among HIV-Positive people in British Columbia, Canada," PLoS ONE, vol. 7, no. 7, Article ID e40793, 2012.

[183] D. Hooshyar, J. Goulet, L. Chwastiak et al., "Time to depression treatment in primary care among HIV-infected and uninfected veterans," Journal of General Internal Medicine, vol. 25, no. 7, pp. 656-662, 2010.

[184] F. B. Del Guerra, J. L. I. Fonseca, V. M. Figueiredo, E. B. Ziff, and E. C. Konkiewitz, "Human immunodeficiency virus-associated depression: contributions of immuno-inflammatory, monoaminergic, neurodegenerative, and neurotrophic pathways," Journal of Neuro Virology, vol. 19, no. 4, pp. 314-327, 2013.

[185] T. Fischer-Smith and J. Rappaport, "Evolving paradigms in the pathogenesis of HIV-1-associated dementia," Expert Reviews in Molecular Medicine, vol. 7, pp. 1-26, 2005.

[186] H.-M. Gao, J. Jiang, B. Wilson, W. Zhang, J.-S. Hong, and B. Liu, "Microglial activation-mediated delayed and progressive degeneration of rat nigral dopaminergic neurons: relevance to Parkinson's disease," Journal of Neurochemistry, vol. 81, no. 6, pp. 1285-1297, 2002.

[187] M. D. Nguyen, T. D’Aigle, G. Gowing, J.-P. Julien, and S. Rivest, "Exacerbation of motor neuron disease by chronic stimulation of innate immunity in a mouse model of amyotrophic lateral sclerosis," Journal of Neuroscience, vol. 24, no. 6, pp. 1340-1349, 2004.
[188] O. Andersen, P.-E. Lygner, T. Bergstrom, M. Andersson, and A. Vahlne, "Viral infections trigger multiple sclerosis relapses: a prospective seroepidemiological study," Journal of Neurology, vol. 240, no. 7, pp. 417-422, 1993.

[189] W. A. Sibley, C. R. Bamford, and K. Clark, "Clinical viral infections and multiple sclerosis," The Lancet, vol. 1, no. 8441, pp. 1313-1315, 1985.

[190] S. Y. Shin, P. Katz, M. Wallhagen, and L. Julian, "Cognitive impairment in persons with rheumatoid arthritis," Arthritis Care \& Research, vol. 64, no. 8, pp. 1144-1150, 2012.

[191] R. M. Carbotte, S. D. Denburg, and J. A. Denburg, "Prevalence of cognitive impairment in systemic lupus erythematosus," Journal of Nervous and Mental Disease, vol. 174, no. 6, pp. 357364, 1986.

[192] R. Dantzer, J. C. O’Connor, G. G. Freund, R. W. Johnson, and K. W. Kelley, "From inflammation to sickness and depression: when the immune system subjugates the brain," Nature Reviews Neuroscience, vol. 9, no. 1, pp. 46-56, 2008.

[193] V. H. Perry, C. Cunningham, and C. Holmes, "Systemic infections and inflammation affect chronic neurodegeneration," Nature Reviews Immunology, vol. 7, no. 2, pp. 161-167, 2007.

[194] M. T. Heneka, M. P. Kummer, and E. Latz, "Innate immune activation in neurodegenerative disease," Nature Reviews Immunology, vol. 14, no. 7, pp. 463-477, 2014.

[195] A. J. McMichael, P. Borrow, G. D. Tomaras, N. Goonetilleke, and B. F. Haynes, "The immune response during acute HIV-1 infection: clues for vaccine development," Nature Reviews Immunology, vol. 10, no. 1, pp. 11-23, 2010.

[196] J. E. Bell, A. Busuttil, J. W. Ironside et al., "Human immunodeficiency virus and the brain: investigation of virus load and neuropathologic changes in pre-AIDS subjects," Journal of Infectious Diseases, vol. 168, no. 4, pp. 818-824, 1993.

[197] R. Ciccocioppo, A. di Sabatino, R. Parroni et al., "Increased enterocyte apoptosis and Fas-Fas ligand system in celiac disease," The American Journal of Clinical Pathology, vol. 115, no. 4, pp. 494-503, 2001.

[198] Ó. P. Rojo, A. L. San Román, E. A. Arbizu, A. D. L. H. Martínez, E. R. Sevillano, and A. A. Martínez, "Serum lipopolysaccharidebinding protein in endotoxemic patients with inflammatory bowel disease," Inflammatory Bowel Diseases, vol. 13, no. 3, pp. 269-277, 2007.

[199] N. G. Sandler, C. Koh, A. Roque et al., "Host response to translocated microbial products predicts outcomes of patients with HBV or HCV infection," Gastroenterology, vol. 141, no. 4, pp. 1230.e1-1230.e3, 2011.

[200] N. G. Sandler, H. Wand, A. Roque et al., "Plasma levels of soluble CD14 independently predict mortality in HIV infection," Journal of Infectious Diseases, vol. 203, no. 6, pp. 780-790, 2011.

[201] W. Jiang, M. M. Lederman, P. Hunt et al., "Plasma levels of bacterial DNA correlate with immune activation and the magnitude of immune restoration in persons with antiretroviraltreated HIV infection," Journal of Infectious Diseases, vol. 199, no. 8, pp. 1177-1185, 2009.

[202] M. Kramski, A. J. Gaeguta, G. F. Lichtfuss et al., "Novel sensitive real-time PCR for quantification of bacterial 16S rRNA genes in plasma of HIV-infected patients as a marker for microbial translocation," Journal of Clinical Microbiology, vol. 49, no. 10, pp. 3691-3693, 2011.

[203] P. Ancuta, A. Kamat, K. J. Kunstman et al., "Microbial translocation is associated with increased monocyte activation and dementia in AIDS patients," PLoS ONE, vol. 3, no. 6, Article ID e2516, 2008. 
[204] J. D. Estes, L. D. Harris, N. R. Klatt et al., "Damaged intestinal epithelial integrity linked to microbial translocation in pathogenic simian immunodeficiency virus infections," PLoS Pathogens, vol. 6, no. 8, Article ID e1001052, 2010.

[205] J. M. Brenchley, D. A. Price, T. W. Schacker et al., "Microbial translocation is a cause of systemic immune activation in chronic HIV infection," Nature Medicine, vol. 12, no. 12, pp. 1365-1371, 2006.

[206] R. S. Veazey, M. DeMaria, L. V. Chalifoux et al., "Gastrointestinal tract as a major site of $\mathrm{CD} 4^{+} \mathrm{T}$ cell depletion and viral replication in SIV infection," Science, vol. 280, no. 5362, pp. 427431, 1998.

[207] M. Guadalupe, E. Reay, S. Sankaran et al., "Severe CD $4^{+}$Tcell depletion in gut lymphoid tissue during primary human immunodeficiency virus type 1 infection and substantial delay in restoration following highly active antiretroviral therapy," Journal of Virology, vol. 77, no. 21, pp. 11708-11717, 2003.

[208] J. M. Brenchley, T. W. Schacker, L. E. Ruff et al., "CD4 ${ }^{+}$T cell depletion during all stages of HIV disease occurs predominantly in the gastrointestinal tract," The Journal of Experimental Medicine, vol. 200, no. 6, pp. 749-759, 2004.

[209] D. Sharpstone, P. Neild, R. Crane et al., "Small intestinal transit, absorption, and permeability in patients with AIDS with and without diarrhoea," Gut, vol. 45, no. 1, pp. 70-76, 1999.

[210] E. Cassol, V. Misra, A. Dutta, S. Morgello, and D. Gabuzda, "Cerebrospinal fluid metabolomics reveals altered waste clearance and accelerated aging in HIV patients with neurocognitive impairment," AIDS, vol. 28, no. 11, pp. 1579-1591, 2014.

[211] S. L. Risacher and A. J. Saykin, "Neuroimaging biomarkers of neurodegenerative diseases and dementia," Seminars in Neurology, vol. 33, no. 4, pp. 386-416, 2013.

[212] G. E. Martin, M. Gouillou, A. C. Hearps et al., "Age-associated changes in monocyte and innate immune activation markers occur more rapidly in HIV infected women," PLoS ONE, vol. 8, no. 1, Article ID e55279, 2013.

[213] N. Thieblemont, L. Weiss, H. M. Sadeghi, C. Estcourt, and N. Haeffner-Cavaillon, "CD14 ${ }^{\text {low }} \mathrm{CD} 16^{\text {high }}$ : a cytokine-producing monocyte subset which expands during human immunodeficiency virus infection," European Journal of Immunology, vol. 25, no. 12, pp. 3418-3424, 1995.

[214] C. Locher, G. Vanham, L. Kestens, M. Kruger, J. L. Ceuppens, and J. Vingerhoets, "Expression patterns of Fc $\gamma$ receptors, HLADR and selected adhesion molecules on monocytes from normal and HIV-infected individuals," Clinical and Experimental Immunology, vol. 98, no. 1, pp. 115-122, 1994.

[215] J. B. Allen, H. L. Wong, P. M. Guyre, G. L. Simon, and S. M. Wahl, "Association of circulating receptor Fc $\gamma$ RIII-positive monocytes in AIDS patients with elevated levels of transforming growth factor- $\beta$," Journal of Clinical Investigation, vol. 87, no. 5, pp. 1773-1779, 1991.

[216] T. Fischer-Smith, E. M. Tedaldi, and J. Rappaport, "CD163/ CD16 coexpression by circulating monocytes/macrophages in HIV: potential biomarkers for HIV infection and AIDS progression," AIDS Research and Human Retroviruses, vol. 24, no. 3, pp. 417-421, 2008.

[217] L. Pulliam, R. Gascon, M. Stubblebine, D. McGuire, and M. S. McGrath, "Unique monocyte subset in patients with AIDS dementia," The Lancet, vol. 349, no. 9053, pp. 692-695, 1997.

[218] T. Fischer-Smith, S. Croul, A. E. Sverstiuk et al., "CNS invasion by CD14+/CD16+ peripheral blood-derived monocytes in HIV dementia: perivascular accumulation and reservoir of HIV infection," Journal of Neurovirology, vol. 7, no. 6, pp. 528-541, 2001.

[219] T. Fischer-Smith, C. Bell, S. Croul, M. Lewis, and J. Rappaport, "Monocyte/macrophage trafficking in acquired immunodeficiency syndrome encephalitis: lessons from human and nonhuman primate studies," Journal of NeuroVirology, vol. 14, no. 4, pp. 318-326, 2008.

[220] T. Fischer-Smith, S. Croul, A. Adeniyi et al., "Macrophage/ microglial accumulation and proliferating cell nuclear antigen expression in the central nervous system in human immunodeficiency virus encephalopathy," American Journal of Pathology, vol. 164, no. 6, pp. 2089-2099, 2004. 


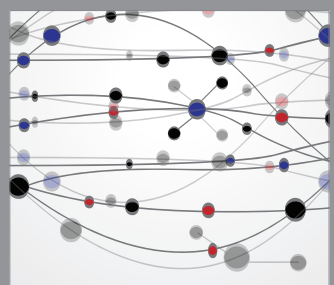

The Scientific World Journal
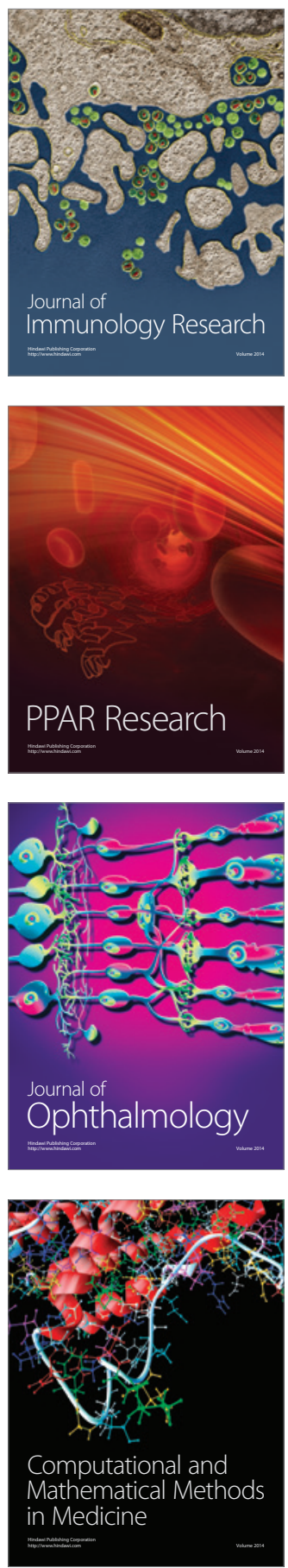

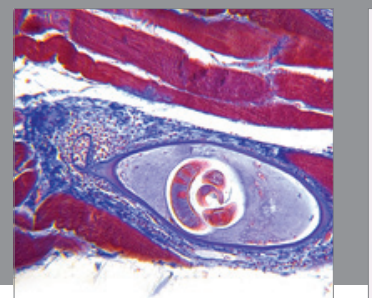

Gastroenterology

Research and Practice
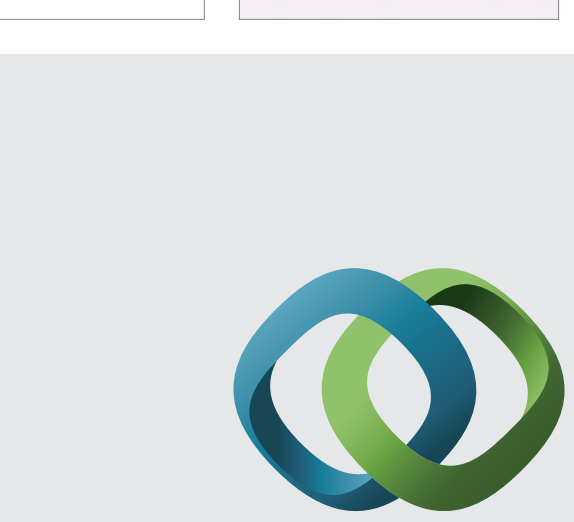

\section{Hindawi}

Submit your manuscripts at

http://www.hindawi.com
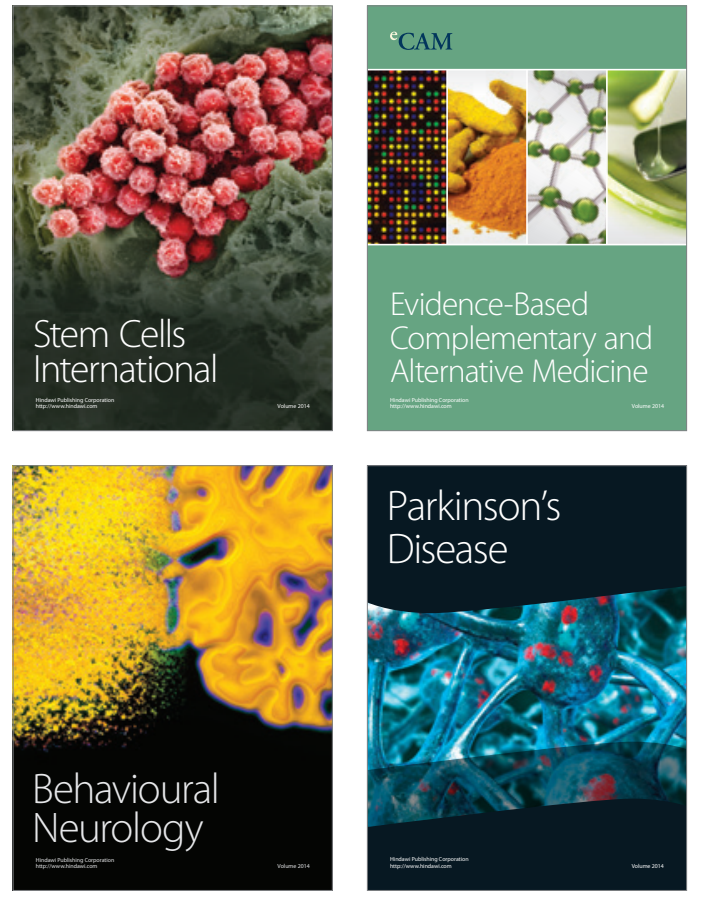
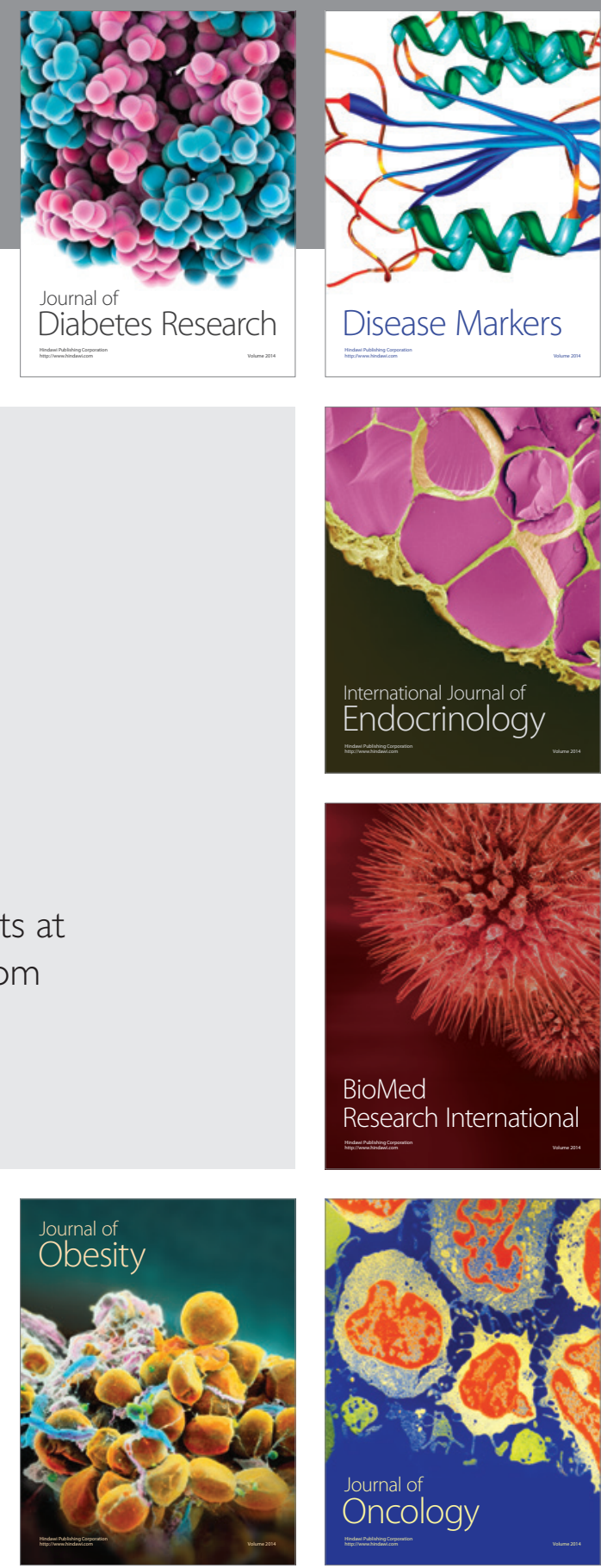

Disease Markers
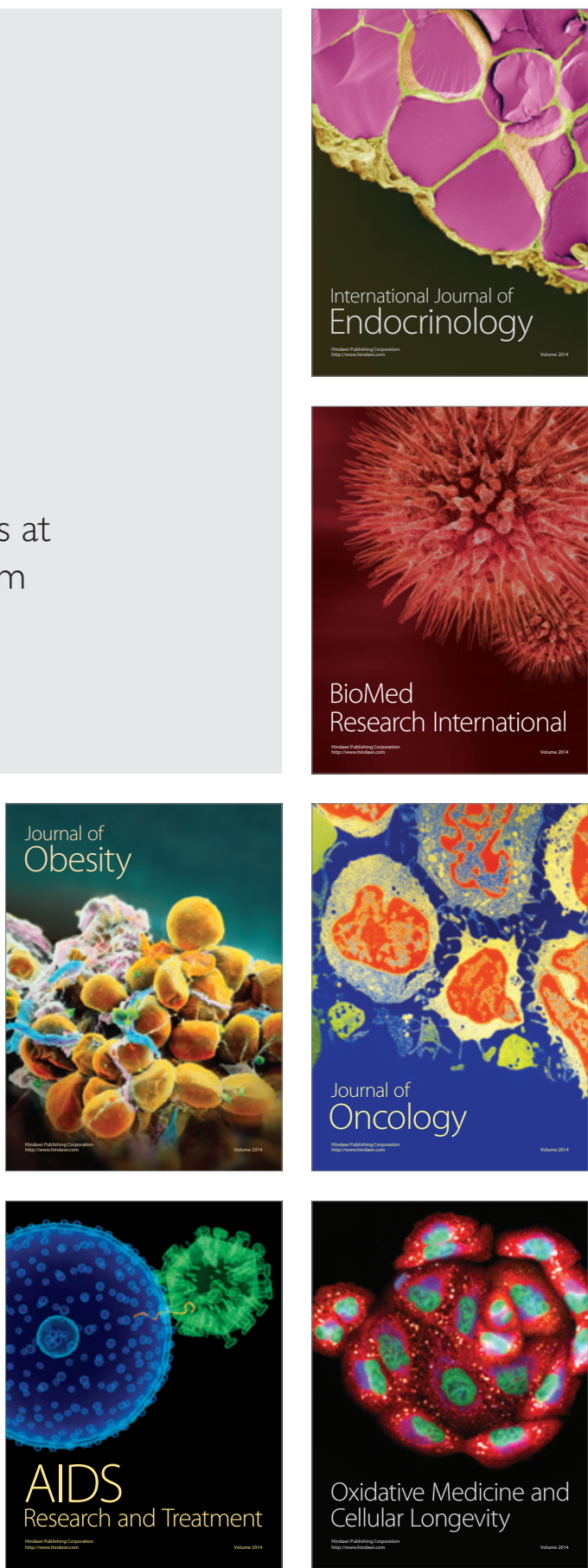